\title{
Circulation responses to snow albedo feedback in climate change
}

\author{
Christopher G. Fletcher, ${ }^{1}$ Paul J. Kushner, ${ }^{1}$ Alex Hall, ${ }^{2}$ and Xin $\mathrm{Qu}^{2}$ \\ Received 3 March 2009; revised 29 March 2009; accepted 1 April 2009; published 2 May 2009.
}

[1] Climate change is expected to cause a reduction in the spatial extent of snow cover on land. Recent work suggests that this will exert a local influence on the atmosphere and the hydrology of snow-margin areas through the snowalbedo feedback (SAF) mechanism. A significant fraction of variability among IPCC AR4 general circulation model (GCM) predictions for future summertime climate change over these areas is related to the models' representation of springtime SAF. In this study, we demonstrate a nonlocal influence of SAF on the summertime circulation in the extratropical Northern Hemisphere. Increased land surface warming in models with stronger SAF is associated with large-scale sea-level pressure anomalies over the northern oceans and a poleward intensified subtropical jet. We find that up to $25-30 \%$ and, on average, $5-10 \%$ of the intermodel spread in projections of the circulation response to climate change is linearly related to SAF strength. Citation: Fletcher, C. G., P. J. Kushner, A. Hall, and X. Qu (2009), Circulation responses to snow albedo feedback in climate change, Geophys. Res. Lett., 36, L09702, doi:10.1029/ 2009GL038011.

\section{Introduction}

[2] Recent work has shown that the strength of simulated snow albedo feedback (SAF) varies by a factor of three among the suite of general circulation models used in the Fourth Assessment Report (AR4) of the Intergovernmental Panel on Climate Change [Intergovernmental Panel on Climate Change (IPCC), 2007; Qu and Hall, 2007]. This spread is explained mostly by the spread in the albedo values of snow-covered surfaces among the different models [Qu and Hall, 2007]. Limited observational data has made it difficult to obtain a realistic reference value for SAF. The range in the models' SAF strength is shown to have a direct impact on the spread in projections of climate change over the continental interior of North America [Hall et al., 2008]. Models with stronger SAF predict that summers will become warmer and drier than summers in models with weaker SAF.

[3] Alongside the spread in model projections of changes to the land surface, there are also significant inter-model variations among projections of changes to regional and hemispheric atmospheric circulation patterns [Osborn, 2004; Miller et al., 2006]. Based on our knowledge of the

\footnotetext{
${ }^{1}$ Department of Physics, University of Toronto, Toronto, Ontario, Canada.

${ }^{2}$ Department of Atmospheric and Oceanic Sciences, University of California, Los Angeles, California, USA.
}

summertime climate, the expectation is that regional warming and drying at the surface will be accompanied by regional-scale changes to the atmospheric circulation and stratification. But it is less obvious whether such regional responses could extend into larger scale teleconnected patterns, i.e., circulation responses away from the continental interiors where SAF is expected to be strongest. Here, we investigate whether the variation in SAF among climate models has a systematic projection onto the atmospheric circulation response to climate change across the entire Northern Hemisphere.

[4] While previous work has focused on the details of the many radiative feedback processes themselves [e.g., Bony et al., 2006], the link between the atmospheric circulation response to anthropogenic forcing and a specific radiative feedback, such as SAF, has not been previously explored. In this letter, we demonstrate that SAF is linearly related not only to the spread of the surface temperature responses to climate change, but also to the spread of atmospheric circulation responses. This hemispheric-scale signal is most significant close to the surface, but is also found to project onto the zonal mean circulation in the form of a poleward intensification of the subtropical jet. We quantify the influence of SAF and find that up to $25-30 \%$ and, on average, $5-10 \%$ of the inter-model spread in projections of the circulation response to climate change is linearly related to SAF strength.

\section{Data and Methods}

[5] All data are taken from the World Climate Research Programme's (WCRP's) Coupled Model Intercomparison Project phase 3 (CMIP3) multi-model dataset. We use 17 of the 18 CMIP3 models examined by $Q u$ and Hall [2007] (henceforth "the models"); the exception being the ECHO$\mathrm{G}$ model, which did not provide data on pressure levels. We define the response to climate change as the difference between the time average fields for the 2100s (SRESA1B scenario) minus the $1900 \mathrm{~s}$ (20c3m experiment).

[6] The period of analysis is the summer season, when Hall et al. [2008] found a strong influence of SAF on surface warming and the hydrological cycle; all figures are presented for the June-July-August (JJA) mean. We use an index of SAF as described by Qu and Hall [2007]. The SAF index is calculated as the ratio of the response to climate change in surface albedo over the response to climate change in surface temperature during spring (MarchApril-May) over land areas poleward of $30^{\circ} \mathrm{N}$. The spring season is representative of SAF strength throughout the year [Qu and Hall, 2007]. 

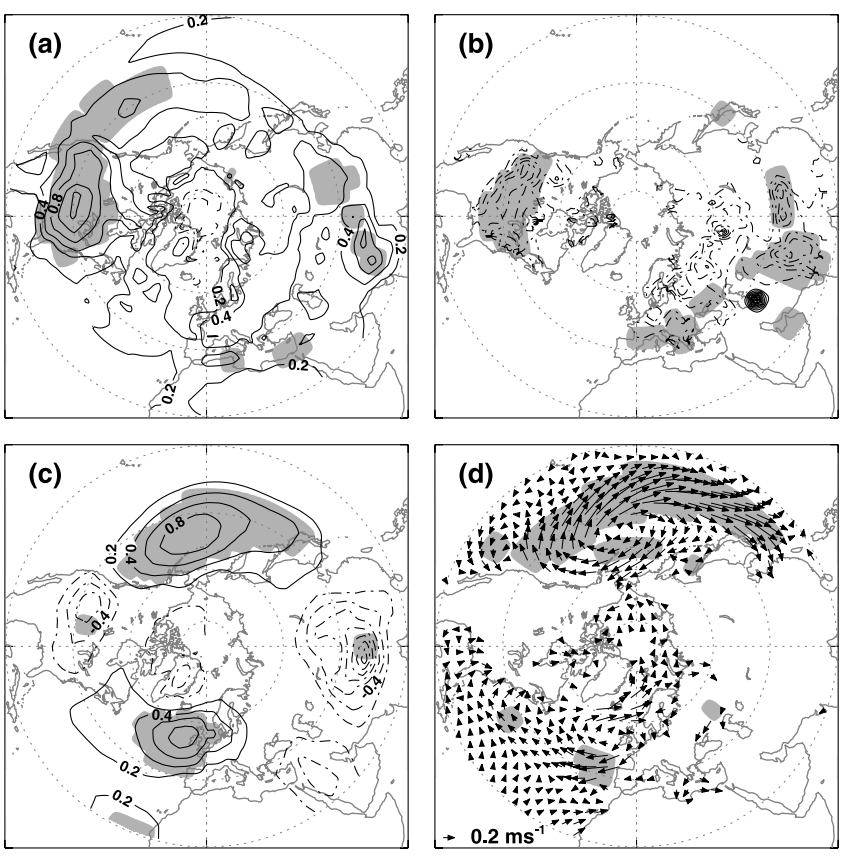

Figure 1. (a) Projection of the response to climate change (defined as the difference between the time means for the 22nd Century and the 20th Century) in surface temperature on the snow albedo feedback (SAF) index (see text for details). (b) Same as Figure la except for soil moisture. (c) Same as Figure 1a except for mean sea level pressure. (d) Same as Figure 1a except for $1000 \mathrm{hPa}$ wind vectors. Contour interval is $0.2 \mathrm{~K}$ (Figure $1 \mathrm{a}$ ), $7.5 \mathrm{Kg} \mathrm{m}^{-2}$ (Figure $1 \mathrm{~b}$ ) and $0.2 \mathrm{hPa}$ and negative contours are dashed (Figure 1c). Reference wind vector is shown in bottom left of Figure 1d. Shading in Figures 1-3 denotes responses that are statistically significant $(p<0.05)$ as determined by a Student's $t$-test.

[7] Summertime mean fields of the response to climate change are projected onto this index to form a pattern $\mathbf{Y}$,

$$
\mathbf{Y}=\frac{\mathbf{X}^{T} \mathbf{S}}{\mathbf{S}^{T} \mathbf{S}}
$$

where $\mathbf{X}$ is the size $\mathrm{M} \times \mathrm{N}$ matrix containing the values of the response at $\mathrm{M}$ gridpoint locations for $\mathrm{N}$ models, $\mathbf{S}$ is the size N matrix of SAF values and $\mathbf{S}^{T} \mathbf{S}=(n-1) s_{y}^{2}$ and $s_{y}$ is the sample standard deviation of $\mathbf{S}$ [Baldwin et al., 2009]. Therefore, at each grid point $\mathbf{Y}$ represents the response in $\mathbf{X}$ per unit standard deviation in the SAF index.

[8] Each of the models assessed in this study predicts a warming response to climate change in JJA mean surface temperature over Northern Hemisphere (NH) land areas. However, the amplitude of the warming varies in the range 2.6-6.2 K with a mean of $4.4 \mathrm{~K}$ per 200 years. Since the external radiative forcing is identical in all models, the spread in the temperature predictions must result from differences in the models' internal climate feedbacks, of which SAF is a likely contributor over extratropical land areas [Qu and Hall, 2007].

\section{Results}

\subsection{Surface Response Associated With SAF}

[9] Figure 1a shows that models with stronger SAF produce a larger surface warming response to climate change. This is especially evident over the midlatitude regions of the $\mathrm{NH}$ continents, where local amplification of the greenhouse gas-induced warming is expected due to SAF [IPCC, 2007, section 4.2.2.1]. In agreement with Hall et al. [2008, Figure 2a] the strongest and most significant warming response is located over the continental United States, where recent negative trends in springtime snow cover are largest [Groisman et al., 2004; Barnett et al., 2008]. Hall et al. [2008] showed that the summertime warming response is linked to spring SAF through reduced winter/spring snow mass, a reduction in snow meltwater available for storage in the soil and a subsequent decrease in evapotranspiration, which leads to a relative increase in sensible over latent heating.

[10] A similar temperature response is seen over Eurasia but it is weaker than over North America because SAF is associated with relatively less drying over a large region of eastern Eurasia (Figure 1b). By contrast, the drying is more uniform across the central United States. Consequently, the increase in sensible over latent heating is larger over North America than over Eurasia (not shown), which causes a stronger positive temperature feedback.

[11] We find that SAF is also associated with nonlocal circulation changes. This is suggested by an area of signif-
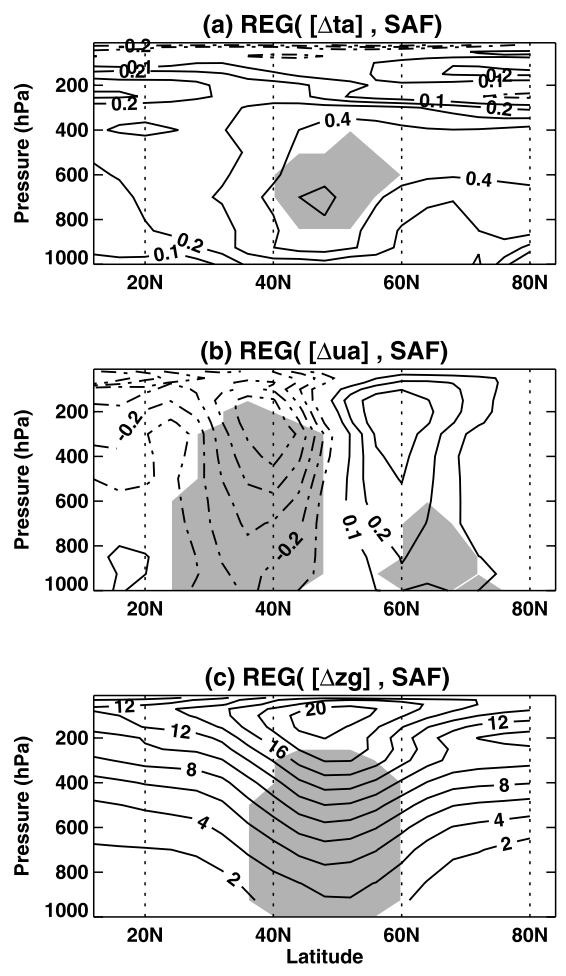

Figure 2. As Figure 1a except fields plotted are (a) zonal mean temperature $([\Delta \mathrm{ta}])$, (b) zonal mean zonal wind

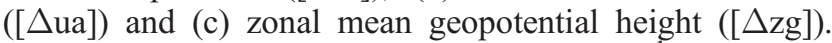
Contour interval is $0.1 \mathrm{~K}$ (Figure $2 \mathrm{a}$ ), $0.1 \mathrm{~m} \mathrm{~s}^{-1}$ (Figure $2 \mathrm{~b}$ ) and $2 \mathrm{~m}$ and negative contours are dashed (Figure $2 \mathrm{c}$ ). 


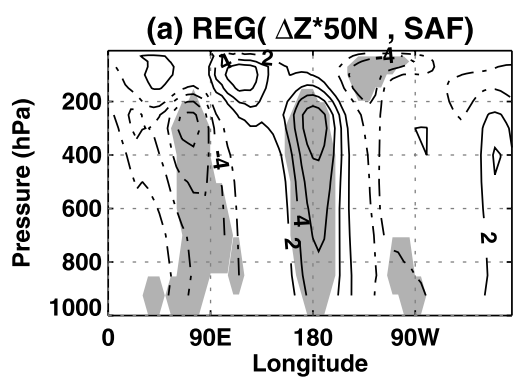

(b) REG( $\left.\triangle Z 500^{*}, \mathrm{SAF}\right)$

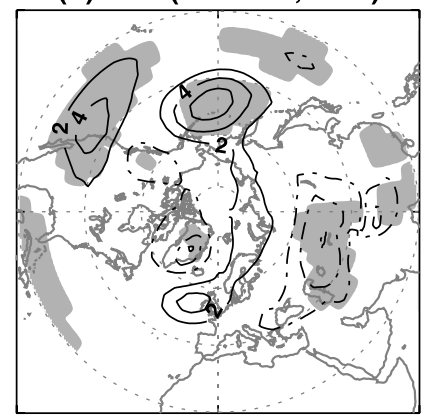

Figure 3. As Figure 1a except fields plotted are (a) eddy geopotential height along $50^{\circ} \mathrm{N}(\triangle \mathrm{Z} * 50 \mathrm{~N})$ and (b) eddy geopotential height at $500 \mathrm{hPa}\left(\Delta \mathrm{Z} 500^{*}\right)$. Contour interval is $2 \mathrm{~m}$ and negative contours are dashed.

icant warming over the North Pacific (Figure 1a), and clearly shown in the sea level pressure (SLP) response (Figure 1c) with opposite-signed anomalies between the continents and northern oceans. This pattern suggests that in models with stronger SAF the land surface warms faster than the ocean, driving surface convergence over the land and divergence over the ocean. The significant response over the Azores and Aleutian regions indicates a poleward intensification of the quasi-permanent high pressure patterns there. The near-surface wind response also reflects this poleward shift, with the climatological westerlies strengthened around $60^{\circ} \mathrm{N}$ and weakened around $40^{\circ} \mathrm{N}$ (Figure 1d).

[12] Over the Arctic basin the surface responses associated with SAF are very weak (Figures 1a, 1c, and 1d), which suggests that SAF is not related to surface warming or circulation changes in that region. By contrast, the sea-ice albedo feedback has been shown to significantly amplify climate change over the Arctic in observations [Deser et al., 2000] and models [Holland and Bitz, 2003]. The simulated response associated with SAF therefore appears to be uncorrelated with sea-ice albedo feedback in these models.

\subsection{Response in the Free Troposphere}

[13] The association between SAF and the circulation response to climate change is not confined to the surface. Figure 2 shows a vertically coherent response throughout much of the troposphere that projects significantly onto the zonal mean circulation. Stronger SAF is related to a broad region of mid-tropospheric warming centered on $50^{\circ} \mathrm{N}$ (Figure 2a) and a dipolar zonal wind response that peaks in the upper troposphere and that appears to be in thermal wind balance with the warming (Figure $2 \mathrm{~b}$ ). Consistently, the geopotential response corresponds to increased thickness throughout the troposphere in the $40^{\circ} \mathrm{N}-60^{\circ} \mathrm{N}$ region where SAF is strongest (Figure 2c). Thus SAF, which represents how GCMs simulate snow-related land surface processes, is linked to a deep zonal-mean response of the atmospheric general circulation. This zonal mean response connects stronger SAF with a poleward shifted subtropical jet (Figure $2 \mathrm{~b}$ ) and with relatively enhanced dry static stability in the midlatitude lower troposphere (Figure 2a). To our knowledge such a link has not been previously discussed and would probably not have been predicted a priori.

[14] Interestingly, the dynamical response to climate change associated with SAF also has a zonally asymmetric component. In particular, there is a weak but significant projection onto the summertime quasi-stationary eddies along $50^{\circ} \mathrm{N}$ (Figure 3a). Over Eurasia and the North Pacific the response is equivalent barotropic and amplifies with height, indicating a Rossby wave train response. By contrast, over North America the response is surface-trapped, with the low in sea-level pressure (Figure 1c) overlain by a mid-tropospheric high in geopotential height (Figure 3b). We discuss possible causes of this asymmetry in section 4 .

\subsection{Reduction in the Spread of Projections}

[15] Following Hall et al. [2008] we next investigate whether any of the spread in the projections of the circulation response to climate change can be explained by the relationship between the circulation and SAF. Hall et al. [2008] found a one-third reduction in the inter-model standard deviation of projections of the surface temperature response over the United States after removing the component of the response that was linearly related to SAF.

[16] In Figure 4 we employ a similar diagnostic to grids of NH surface temperature, sea-level pressure and $1000 \mathrm{hPa}$ winds. The largest reductions in the spread among the models are observed where the strongest and most significant responses were seen in Figure 1. In particular, the spread is reduced by up to $25-30 \%$ and, on average, by $5-$ $10 \%$ in surface temperature over North America and Eurasia (Figure 4a), sea-level pressure over the Aleutian and Azores regions (Figure 4b) and $1000 \mathrm{hPa}$ wind over the North Pacific basin (Figure 4c). These results extend the work of Hall et al. [2008] to the hemispheric scale and demonstrate that improved accuracy in the model representation of SAF could help to constrain the inter-model spread in predictions of the circulation response to climate change.

\section{Discussion and Conclusions}

[17] We have shown that projections of the summertime atmospheric circulation response to climate change among 17 CMIP3 models contain a component that is significantly related to the strength of the simulated snow-albedo feedback (SAF). Models with stronger SAF are associated with increased warming over continental interiors, formation of collocated thermal low pressure centers and an intensification of the quasi-permanent summertime high pressure systems over the North Pacific and North Atlantic basins. This response projects onto the zonal mean circulation as a poleward intensified subtropical jet. The most significant signal is located in the Northern Hemisphere midlatitudes; SAF does not appear to be related to circulation changes over higher latitude regions.

[18] The evidence presented in this letter supports the hypothesis that the strength of SAF exerts a direct control 

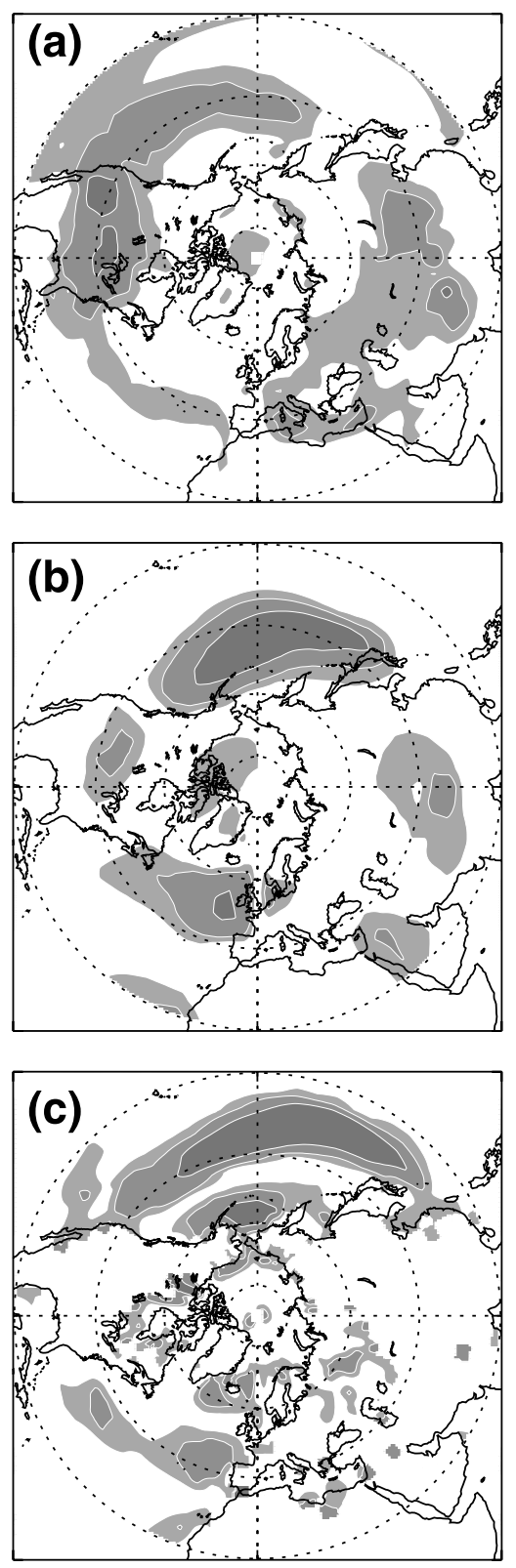

Figure 4. The percentage reduction in the inter-model standard deviation of responses to climate change after the component linearly related to SAF is removed. At each grid location we perform a linear least-squares fit between $\mathrm{SAF}$ and the response variable; the regression residuals are employed to plot $\left(\sigma_{\text {SAF REMOVED }} / \sigma_{\text {TOTAL }}\right) \times 100 \%$ for (a) surface temperature, (b) sea-level pressure and (c) 1000 $\mathrm{hPa}$ winds. Contour interval is $5 \%$, shading begins at $5 \%$.

over the atmospheric circulation response to climate change in the models. While we acknowledge that our analysis method cannot distinguish cause from effect, we believe that this line of reasoning is physically more plausible than the alternative hypothesis, where a systematic part of the atmospheric response to greenhouse gas forcing among 17 models causes a surface amplification that is similar in character to SAF. Careful modeling studies will be required to fully determine a causal link.

[19] Our results highlight an asymmetry between Eurasia and North America in both the surface (Figure 1a) and free tropospheric (Figure 3a) response associated with SAF. Déry and Brown [2007] showed that in observations the largest SAF potential is found over Eurasia, whereas we find the strongest response over North America. It is unclear whether these differences are caused by dynamics or by deficiencies in the models' land surface schemes. In a separate analysis (not shown) we have found that the regions over which the models are sensitive to SAF are different from observations, particularly over Eurasia. However, dynamics could also play a role, since the planetary wave response to surface perturbations over Eurasia is enhanced by the presence of high topography, whereas over North America the response is less sensitive to topographic barriers [Gong et al., 2004]. Investigation into these issues is ongoing.

[20] Acknowledgments. We acknowledge the modeling groups, the Program for Climate Model Diagnosis and Intercomparison (PCMDI) and the WCRP's Working Group on Coupled Modeling (WGCM) for their roles in making available the WCRP CMIP3 multi-model dataset. Support of this dataset is provided by the Office of Science, U.S. Department of Energy. C.G.F and P.J.K acknowledge support from the Canadian International Polar Year Cryosphere Network and Canadian Foundation for Climate and Atmospheric Sciences.

\section{References}

Baldwin, M. P., D. B. Stephenson, and I. T. Joliffe (2009), Spatial weighting and iterative projection methods for EOFs, J. Clim., 22(2), 234-243.

Barnett, T. P., et al. (2008), Combining a regional hydrologic and global climate model implies that human-caused $\mathrm{CO}_{2}$ emissions have already greatly changed river flows and snow pack in the western United States, Science, 319(5866), 1080-1082, doi:10.1126/science.1152538.

Bony, S., et al. (2006), How well do we understand and evaluate climate change feedback processes?, J. Clim., 19(3), 3445-3482.

Déry, S. J., and R. D. Brown (2007), Recent Northern Hemisphere snow cover extent trends and implications for the snow-albedo feedback, Geophys. Res. Lett., 34, L22504, doi:10.1029/2007GL031474.

Deser, C., J. Walsh, and M. Timlin (2000), Arctic sea ice variability in the context of recent atmospheric circulation trends, J. Clim., 13(3), $617-633$.

Gong, G., D. Entekhabi, and J. Cohen (2004), Orographic constraints on a modeled Siberian snow-tropospheric-stratospheric teleconnection pathway, J. Clim., 17(6), 1176-1189.

Groisman, P., R. Knight, T. Karl, D. Easterling, B. Sun, and J. Lawrimore (2004), Contemporary changes of the hydrological cycle over the contiguous United States: Trends derived from in situ observations, J. Hydrometeorol., 5(1), 64-85.

Hall, A., X. Qu, and J. D. Neelin (2008), Improving predictions of summer climate change in the United States, Geophys. Res. Lett., 35, L01702, doi:10.1029/2007GL032012.

Holland, M., and C. Bitz (2003), Polar amplification of climate change in coupled models, Clim. Dyn., 21(3-4), 221-232, doi:10.1007/s00382003-0332-6.

Intergovernmental Panel on Climate Change (IPCC) (2007), Climate Change 2007: The Physical Science Basis. Contribution of Working Group I to the Fourth Assessment Report of the Intergovernmental Panel on Climate Change, edited by S. Solomon et al., 996 pp., Cambridge Univ. Press, Cambridge, U. K.

Miller, R. L., G. A. Schmidt, and D. T. Shindell (2006), Forced annular variations in the 20th century Intergovernmental Panel on Climate Change Fourth Assessment Report models, J. Geophys. Res., 111, D18101, doi:10.1029/2005JD006323

Osborn, T. J. (2004), Simulating the winter North Atlantic Oscillation: The roles of internal variability and greenhouse gas forcing, Clim. Dyn., $22(6-7), 605-623$.

Qu, X., and A. Hall (2007), What controls the strength of snow-albedo feedback?, J. Clim., 20(15), 3971-3981, doi:10.1175/JCLI4186.1.

C. G. Fletcher and P. J. Kushner, Department of Physics, University of Toronto, 60 St. George Street, Toronto, ON M5S 1A7, Canada. (chris.fletcher@utoronto.ca)

A. Hall and X. Qu, Department of Atmospheric and Oceanic Sciences, University of California, 7955 Math Sciences Building, 405 Hilgard Avenue, Los Angeles, CA 90095, USA. 